\title{
Algorithm For The Techno-Economic Optimization Applied In Projects Of Wind Parks Of Latin America.
}

\author{
L. A. Enríquez García ${ }^{1}$, L.J. García Faure ${ }^{2}$, C.S. Oro Ortíz ${ }^{3}$, J.R. Muñoz Cargua ${ }^{4}$ \\ ${ }^{1}$ ESPOCH, MINEDUC, Riobamba, Ecuador. \\ ${ }^{2}$ CEER, U.O, Santiago de Cuba, Cuba. \\ ${ }^{3}$ CEER, U.O, Santiago de Cuba, Cuba. \\ ${ }^{4}$ ESPOCH, Riobamba, Ecuador.
}

\begin{abstract}
: when feasibility studies of energy projects made in general environmental and social factors that promote the project first analyzed, and if it is not rejected or another more attractive energy option is adopted, then the project is ongoing and proceeds to the study technical and economic feasibility. In the case of wind farms, technical feasibility related to the wind potential and its distribution over time and the number of machines that will be used, while the economic viability is obtained by means of the energy produced and different project costs and exploitation. This paper presents an algorithm that has been designed to determine the technical parameters of the project with which the greatest economic benefits of wind farms are obtained develops. To this end, they introduce two important tools: parametric theory to estimate the cost through an equation that establishes the relationship between power, number and height of machines (controllers parameters) with the project capital cost and modeling mathematical optimization, using a model that linked the technical parameters by the economic objective function, in this case the net present value to be maximized. This approach allows technical evaluation studies variants and sensitivity analysis of variables. The implementation of the algorithm may be performed by any software optimization this case the Excel Solver tool is used for ease of implementation and demonstration.
\end{abstract}

Keywords: economic, mathematical model, optimization, projects, wind farms energy

\section{Introduction}

To take advantage efficiently of wind power, it is necessary to have a good knowledge of the characteristics of the wind, such like distribution to short and long term of the magnitude and direction of the speed, turbulence, gusts and extreme speed index. In this way, wind is a manifestation of energy random nature since the variables, previously mentioned, vary with geographical location and time. The best statistical representation of the wind speed is by using the function of density of probability of Weibull, this given by:

$P(v)=\frac{k}{c}\left(\frac{v}{c}\right)^{k-1} \cdot e^{-\left(\frac{v}{c}\right)^{k}}$

Where:

$\mathrm{k}$ - Shape parameter

c - Scale parameter

e - Base of natural logarithm

There are different methods to determine the values of $\mathrm{k}$ and $\mathrm{c}$ from empirical formulas or experimental values. With the increase of $\mathrm{k}$, the probability distribution becomes narrower and vice versa, in the majority of regions of the world its value oscillates around two. The parameter $\mathrm{c}$ bears some relation with the medium speed; usually its value is slightly more than this. Figure 1 shows the distributions of probability values of $\mathrm{k}=1$, $5 ; \mathrm{k}=2$ and $\mathrm{k}=3$, and the value of $\mathrm{c}=6$.

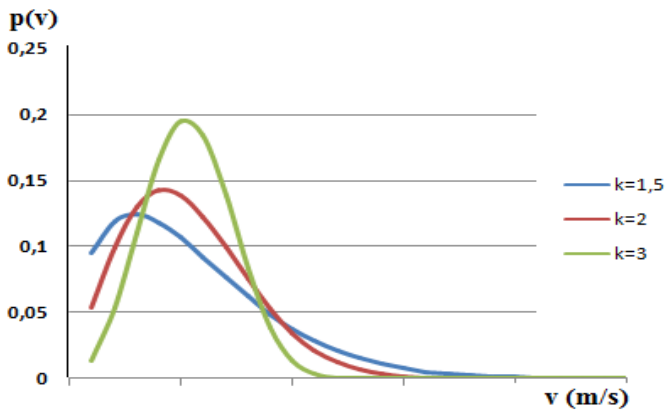


Figure 1. Speed probability distribution.

Known the density probability speeds in a particular site; it is possible to know the wind potential and the power available from the wind. The energy that can be extracted from the air depends on many factors, among them: property and number of machines, the hub height (axis of rotation the blades), availability of machines in the park and others. The algorithm proposed has like objective the determination of the main technical parameters of the project, simultaneously the power and number of machines and height of the cube, with the energy (energy produced and plant factor) and economy (capital cost, rate of return, net present value), through a process of mathematical optimization from the wind potential of the site and the characteristic curves of power-speed of machines that are proposed for the analysis.

\section{Materials And Methods} farms.

The diagram in Figure 2 shows the algorithm followed during the process of optimization of wind

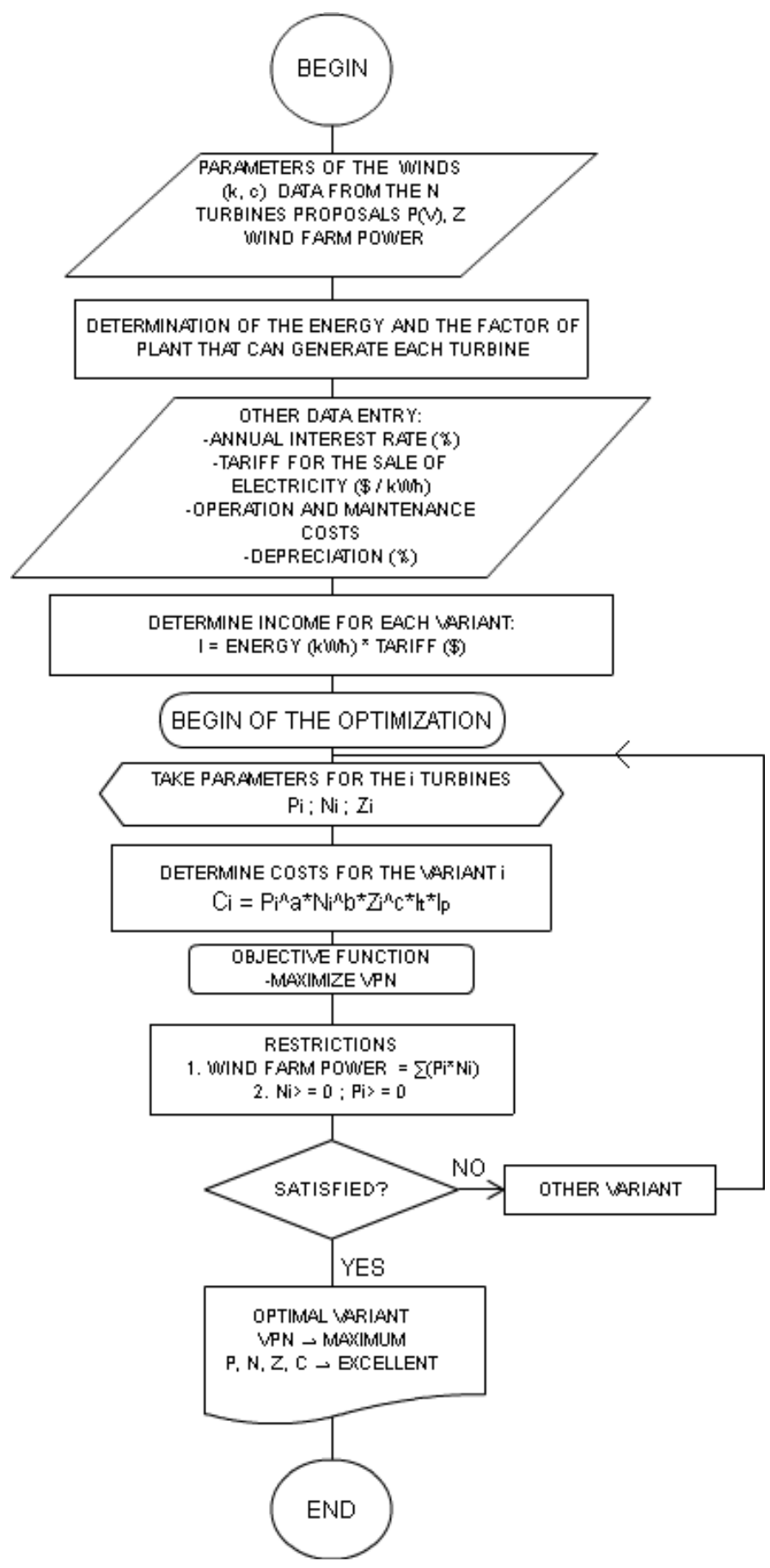


Figure 2. Algorithm for the optimization process

The energy that can be extracted for each type of turbine with the available wind potential is given by:

$E_{i}=t \cdot \int_{v=v a}^{v=v c} p(v) \cdot P_{i}(v) d t$

In which:

$\mathrm{p}(\mathrm{v})$ - Weibull probability function, equation.(1)

$\mathrm{P}_{\mathrm{i}}(\mathrm{v})$ - Characteristic of power - speed turbine $\mathrm{i}$

For the optimization of techno-economic park will have conjugated the following three tools: The parametric estimation of the cost of projects $[1,2,3]$.

- The net present value as a criterion of economic and financial evaluation of projects [4].

- The theory of mathematical optimization [5].

In the first part of the algorithm is determined from the wind potential and the characteristics of the proposed machines, energy and plant each factor could develop. Sometimes to define the best project only by one who guarantees a greater factor of plant, which is a deep mistake, because it may occur, that another smaller plant factor has increased profitability by having a better composition between the number and power of the machines and therefore a lower-cost. This is known as the paradox of the factor of plant [6]. Plant factor is the variation of the generation of energy by atmospheric conditions of the day and time, calculated by the ratio between the power generated into real power and energy generated at rated output.

Parametric cost estimation - unlike the method of estimation the cost or discrete step and other nonparametric methods, the method of parametric estimation, shows the relationship between capital costs and basic technical parameters of the project.

For this work, was developed and evaluated an equation to estimate the cost of wind farms in Latin America and the Caribbean:

$C=18,06 \cdot P^{0,65} \cdot N^{0,928} \cdot H^{1,77} \cdot t^{-0,55} \frac{1,225}{\rho}$

Where:

$\mathrm{P}, \mathrm{N}, \mathrm{H}$ - power, number of machines and the cube height.

$\mathrm{t}$ - Number of years from 2013 taken as reference.

$\rho$ - density of the room air.

The two latter are correction factors or cost indices.

Net Present Value - Using the net present value (NPV) as economic and financial validation criteria because it takes into account the technical parameters indirectly by the equation of the project cost and economic parameters using the energy produced. From the NPV can be established comparisons between different projects perform sensitivity analysis of 7 different variables of the project.

Mathematical model of optimization - After analyzing the different possibilities to choose the objective function, restrictions and variables, was obtained the mathematical model described below:

\section{Objetive Function :}

Maximize NPV $=-C_{C_{i}}+\frac{\sum_{n=1}^{n}(F . C)_{n i}}{(1+i)^{n}}$

In which:

$\mathrm{C}_{\mathrm{Ci}}$ - Project cost with the turbine $\mathrm{i}$

$C_{C i}=\varphi\left(P_{i}, N_{i}, H_{i}, t, \rho\right)$ given by the equation (3)

n- Years of the project

(F.C $)_{\mathrm{ni}}$ - Cash flow for the year $\mathrm{n}$ turbine $\mathrm{i}$

$(F . C)_{n i}=\varphi_{2}\left(E_{n i}, C_{o m i}, i, \ldots\right)$

\section{Restrictions.}

As are analyzed several alternatives (j) to determine the variables $P_{i} y N_{i}$ that offer better results, the problem can be considered mutually exclusive alternatives, in which $(j-1)$ must be excluded. This can be expressed by means of the following restriction: 
$\sum_{j=1}^{j} P_{i} \cdot N_{i}=$ Power park

Where:

$\sum_{j=1}^{j} P_{1} \cdot N_{i}=P_{1} \cdot N_{1}+P_{2} \cdot N_{2}+P_{3} \cdot N_{3}+\cdots(7)$

It must also be met, that:

$P_{i}, N_{i}, H_{1} \geq 0$

Which does not exclude the possibility that $(\mathrm{j}-1)$ restrictions are equal to zero, but the accepted one must be positive.

\section{Variables:}

During the iterative process leading to the optimal value, the decision variables are the fundamental parameters of the machines that determine the cost of the project:

$\mathrm{P}$ - Power machines

$\mathrm{N}$ - Number of machines

$\mathrm{H}$ - Hub height

\begin{tabular}{|c|c|c|c|c|c|}
\hline SHEET 2 & \multicolumn{4}{|c|}{ TECHNO-ECONOMIC OPTIMIZATON } & \\
\hline TYPE TURBINE & NOMINAL P. (Kw) & HUB HEIGHT & ENERGY GENERATED & PLANT FACTOR & \\
\hline$E-48-800$ & 800 & 78 & 3480161,533 & 0,193794495 & \\
\hline$E-44-900$ & 900 & 78 & 3480161,533 & 0,198639357 & \\
\hline \multirow[t]{2}{*}{$E-58-70$} & 850 & 70 & 3587626,451 & 0,481819292 & \\
\hline & \multicolumn{5}{|c|}{ OTHER DATA ENTRY } \\
\hline $\begin{array}{l}\text { POWER PARK (KW) } \\
12000\end{array}$ & $\begin{array}{l}\text { RATE OF RETURN (\%) } \\
5 \% \\
\end{array}$ & $\begin{array}{l}\text { YEARS OF LIFE } \\
20 \\
\end{array}$ & $\begin{array}{l}\text { DEPRECIATION (\% THET.C.) } \\
4\end{array}$ & 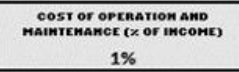 & $\begin{array}{c}\text { TARIFF (\$/KWh) } \\
0,2\end{array}$ \\
\hline \multicolumn{6}{|c|}{ PRELIMINARY CALCULATIONS (NO CHANGE) } \\
\hline $\begin{array}{l}\text { TYPE TURBINE } \\
\text { E-48-800 } \\
\text { E-44-900 } \\
\text { E-58-70 } \\
\end{array}$ & \begin{tabular}{|c|} 
INITIAL COST OF PARK \\
$\$ 14.399 .441,66$ \\
$\$ 0,00$ \\
$\$ 3.988 .044,99$ \\
\end{tabular} & \begin{tabular}{|c|} 
COST OF O. AND M. \\
$\$ 6.960,32$ \\
$\$ 6.960,32$ \\
$\$ 7.175,25$ \\
\end{tabular} & \begin{tabular}{|c|} 
INCOME ELECT. (\$) \\
$\$ 3.629 .808,17$ \\
$\$ 0,00$ \\
$\$ 1.105 .200,74$ \\
\end{tabular} & $\begin{array}{c}\text { RESIDUAL VALUE (\$) } \\
\$ 575.977,67 \\
\$ 0,00 \\
\$ 159.521,80 \\
\end{array}$ & $\begin{array}{c}\text { CASH FLOW P.V. } \\
\$ 27.308 .265,06 \\
-\$ 52.465,45 \\
\$ 8.276 .685,19 \\
\end{array}$ \\
\hline & & OPTIMIZATION MODE & & & \\
\hline \multicolumn{3}{|c|}{ VARIABLES: TYPE AND NUMBERS OF TURBINES } & \multirow{4}{*}{$\begin{array}{l}E-48-800 \\
E-44-900 \\
E-58-70 \\
\end{array}$} & Masinum numern or runeimrs & ROUND OUT \\
\hline \begin{tabular}{l|l}
$E-48-800$ &
\end{tabular} & E-44-900 & $E-58-70$ & & 15 & 15 \\
\hline \multirow[t]{2}{*}{5} & \multirow[t]{2}{*}{0} & \multirow[t]{2}{*}{2} & & 13,33333333 & 14 \\
\hline & & & & 14,11764706 & 15 \\
\hline $\begin{array}{c}\text { OBJECTIVE F. MAXIMUM NPV } \\
\$ 17.144 .998,1\end{array}$ & $\begin{array}{c}\text { Rest. 1 } \\
-6518,749451\end{array}$ & Rest & \begin{tabular}{|l|} 
COST OF PARK \\
ENERGY GENERATED KWH/a
\end{tabular} & $\begin{array}{c}\$ 18.387 .486,65 \\
23.675 .045\end{array}$ & \\
\hline
\end{tabular}

Figure 3. Programming Solver optimization algorithm.

The tool used for optimization - The solution of the mathematical model optimization can be performed by any professional optimization software [6]. For this only, it requires to be programmed the algorithm to follow. If we are analyzed variants with a reduced number of turbines, you can implement a program in Excel in book form with two or three sheets linked together, using the first for the entry to data the park: altitude, terrain roughness, altitude, terrain roughness, the probability for each wind speed, the power values as a function of wind speed for each type of turbine that is to be analyzed and heights of the cube. This sheet is corrected. The values wind speed at the cube height, Calculations of energy generated by each turbine and the plant factor and in the next, sheet is programmed the algorithm used for the optimization process with Excel Solver tool. Figure 3 shows the sheet programmed to analyze the best variant for the project Rosutumbo wind farm in the province of Chimborazo, Republic of Ecuador.

It has the following data:

Weibull distribution: $\mathrm{k}=1,4 ; \mathrm{c}=7$

Wind power density:WPD $=379,4 \mathrm{~W} / \mathrm{m}^{2}$

Air density: $\rho=0,765 \mathrm{~kg} / \mathrm{m}^{3}$

From the energy deficit of the province, it is determined that you need to install $16.8 \mathrm{MW}$. The park project will take $50 \%$ of that power, that is: $\mathrm{P}=8.4 \mathrm{MW}$.

For the techno economic evaluation of this project three types of medium power turbines were selected for easy transport and assembly: Enercon E48-800 y E44-900 the manufacture German and Gamesa G-58-850, 
the manufacture Spanish, loss which was evaluated to determine, which is the most advantageous. The selection took into account the categories recommended by the standards IEC - 61400 concerning extreme winds and turbulence [7].

\section{Results And Discussion}

The results indicate that the best variant is that of Gamesa G -58 wind turbine of $850 \mathrm{~kW}$ with hub height of 70 meters; 10 wind turbines are needed; the cost of the park is approximately $\$ 22,381,745$; and the Net Present Value of the project is $\$ 18,384,701$. By varying one variable at a time to analyze the sensitivity to the VPN. The following results were obtained:

1. The plant factor can only decrease to 0.2. From this value, the NPV becomes negative and the project is not profitable, Figure 4.

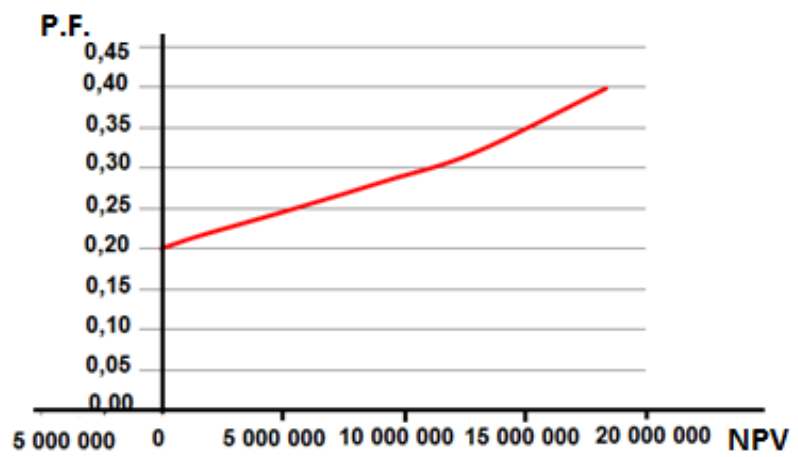

Figure 4. Influence of Plant factor in the NPV.

2. The return rate may increase to $8.2 \%$. Above this value the project ceases to be profitable, Figure 5 .

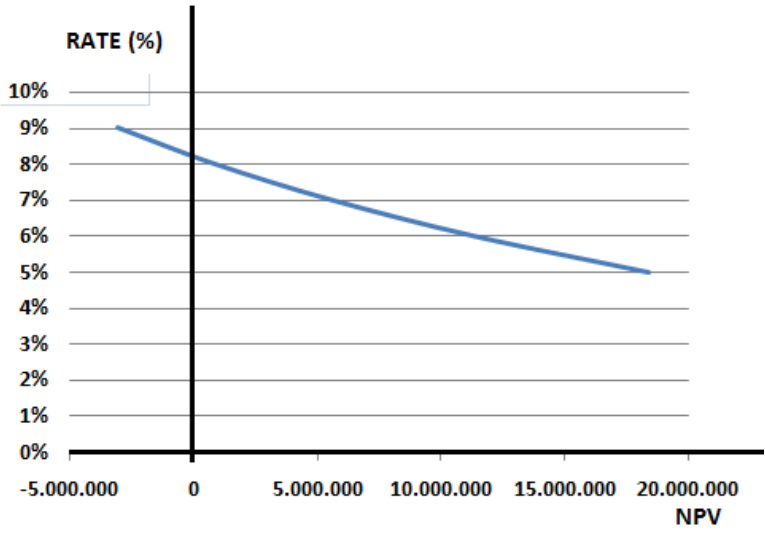

Figure 5. Influence of the rate of return in the NPV.

3. The sale of electricity rate can drop to a price of $\$ 0.12$. Below this value also it ceases to be profitable the project.

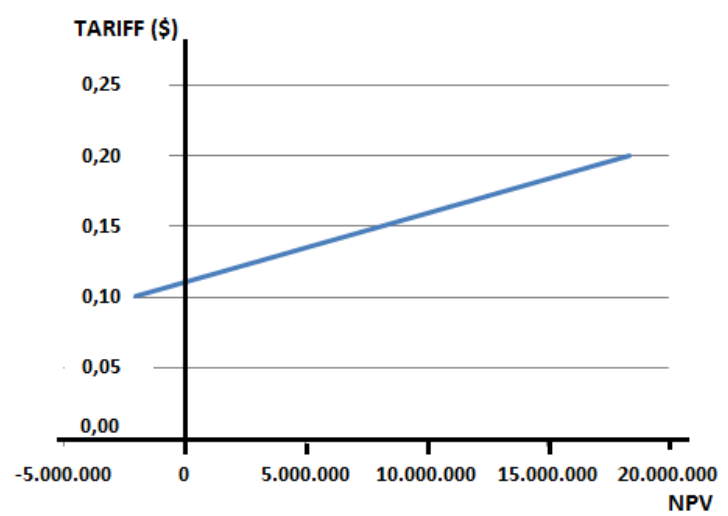

Figure 6. Influence of rate of sale in the NPV. 


\section{Conclusions}

It has been proved the effectiveness of the algorithm developed for simultaneously determining the technical parameters and economic project that optimize wind farms.

It was necessary to link two fundamental tools: Parametric Cost Estimation theory and mathematical optimization technique.

For the first, was formulated an equation for estimating the capital cost of wind farms in the specific conditions of Latin America and the Caribe. For the optimization process, it was necessary to develop the mathematical model from the VPN as objective function to optimize for technical variables linked with economic and ensures sensitivity analyzes.

The algorithm was programmed with the Excel Solver tool for the ease with which this presents for the implementation and demonstration. Its advantages: cost and time reduction in the drafts of wind farms Conduct analysis of variants and has high sensitivity and methodological and demonstrative value, to be able to prove easily, behaviors of technical and economic parameters that otherwise are difficult to understand.

\section{References}

[1]. National Aeronautic and Space Administration. NASA Cost Estimating Handbook. V-4. USA, September/2014.

[2]. Joseph W. Hamaker. The History of NASA Cost Estimating. NASA Cost Estimating Web Site. 2002

[3]. International Society of Parametric Analysis ISPA SCA. Parametric Estimating Handbook. Fourth Esition. Vienna, 2008

[4]. LelandBlank, Anthony Tarquin. Ingeniería Económica. Mc Graw Hill.Bogotá, Colombia. 2002

[5]. Asociación danesa de Energía eólica. Economía de la Energía eólica. www.Danish Windsite.

[6]. Leon Landon, Allan Warren. Optimization with Solver.. www.Solver Web site.

[7]. International Standards IEC- 61400. Wind Turbine Safety Requirements. IEC Web 